\title{
Study of YSZ-based electrochemical sensors with oxide electrodes for high temperature applications
}

\author{
A DUTTA, N KAABBUATHONG, M L GRILli, E DI BARTOLOMEO* and \\ E TRAVERSA \\ Department of Chemical Science and Technology, University of Rome, "Tor Vergata", Via della Ricerca \\ Scientifica, 00133 Rome, Italy
}

\begin{abstract}
Potentiometric sensors based on yttria stabilized zirconia (YSZ) with $\mathrm{WO}_{3}$ as sensing electrode were fabricated using either $\mathrm{Pt}$ or Au electrodes. The sensors were studied in the temperature range 550$700^{\circ} \mathrm{C}$ in the presence of different concentrations $(300-1000 \mathrm{ppm})$ of $\mathrm{NO}_{2}$ and $\mathrm{CO}$ in air. The response to $\mathrm{NO}_{2}$ was very stable with fast response time $(20-40 \mathrm{~s})$. The best sensitivity $(18.8 \mathrm{mV} /$ decade) using Pt electrodes was observed at $600^{\circ} \mathrm{C}$. At the same temperature a cross-sensitivity $(-15 \mathrm{mV} / \mathrm{decade})$ to $\mathrm{CO}$ gas was also noticed. The response to $\mathrm{CO}$ was decreased $\left(-4 \mathrm{mV} /\right.$ decade) using Au electrode. The role played by $\mathrm{WO}_{3}$ on the sensing electrode was discussed.
\end{abstract}

Keywords. Gas sensors; YSZ; oxide electrode.

\section{Introduction}

The environmental concerns have forced the scientists to develop suitable and reliable sensors to detect pollutants such as $\mathrm{NO}_{x}, \mathrm{CO}, \mathrm{HCs}$ etc. Vehicles industries are among the prominent sources of pollution and are encountering norms for pollution control. Therefore, sensors operating at high temperatures $\left(600-700^{\circ} \mathrm{C}\right)$ and in the harsh environment are urgently needed to monitor the level of pollution in the exhaust gases. Solid state electrochemical sensors seem to be the most suitable in such environments. Several reports are available on solid electrolytes based sensors combined with metal ( $\mathrm{Pt}, \mathrm{Au}$ etc) and oxide electrodes for $\mathrm{NO}_{x}$ (Miura and Yamazoe 2000; Grilli et al 2001), CO and HCs (Brosha et al 2000; Hibino et al 2001) detection. Recently, Menil et al (2000) have reviewed the actual trends of these kinds of sensors. The major issues concerning the selectivity and the long term stability are yet to be overcome for sensors for high temperature applications. This fact drives scientists to search for new materials, to improve the device fabrication technique and to go through the sensing mechanism.

In this work we report a study on yttria stabilized zirconia (YSZ) based sensors with $\mathrm{WO}_{3}$ as auxiliary or sensing electrode: ( $\mathrm{Au}) \mathrm{Pt} / \mathrm{YSZ} / \mathrm{Pt}(\mathrm{Au}) / \mathrm{WO}_{3}$. The sensors were studied in the temperature range between 550 and $700^{\circ} \mathrm{C}$ in the presence of $\mathrm{NO}_{2}$ and $\mathrm{CO}$ in air (300$1000 \mathrm{ppm})$. The response was found to be stable, fast and reproducible. Using $\mathrm{Au}$ electrodes instead of Pt the sensors showed a better $\mathrm{NO}_{2}$ selectivity with respect to $\mathrm{CO}$.

\footnotetext{
*Author for correspondence
}

Amperometric measurements were also performed to better understand their sensing mechanism.

\section{Experimental}

YSZ ( $8 \mathrm{~mol} \%$ of $\mathrm{Y}_{2} \mathrm{O}_{3}$ ) pellets of $10 \mathrm{~mm}$ in diameter were used for sensor fabrication. Pt or Au inks were used as electrodes on both sides of the pellets and thin gold wires were connected for current collection. The firing temperatures of $\mathrm{Pt}$ and $\mathrm{Au}$ were $800^{\circ} \mathrm{C}$ for $10 \mathrm{~min}$ and $850^{\circ} \mathrm{C}$ for $10 \mathrm{~min}$, respectively. Commercial $\mathrm{WO}_{3}$ powders $(99.995 \%$ purity) were mixed with a screen-printing oil and the slurry thus obtained was painted on one electrode and fired at $750^{\circ} \mathrm{C}$ for $3 \mathrm{~h}$. Sensing experiments were carried out in a conventional gas-flow apparatus equipped with a controlled heating facility. The sensor environment was alternatively exposed to air and $\mathrm{NO}_{2}$ or CO (300-1000 ppm in air) at the total flow rate of $100 \mathrm{ml} / \mathrm{min}$. Electromotive force (EMF) measurements were performed between the two electrodes of the sensor using a digital electrometer. The electrode with the $\mathrm{WO}_{3}$ coating was always kept at the positive terminal and both the electrodes were exposed to the same gas environment. Amperometric measurements were performed by applying an increasing d.c. voltage (from $-0.6 \mathrm{~V}$ to $+0.4 \mathrm{~V}$ ) and measuring the current output.

\section{Results and discussion}

Figure 1 shows the typical $\mathrm{NO}_{2}$ response of $\mathrm{Pt} / \mathrm{YSZ} /$ $\mathrm{Pt} / \mathrm{WO}_{3}$ sensor at $600^{\circ} \mathrm{C}$. EMF changed quickly upon switching from air to different $\mathrm{NO}_{2}$ concentrations in air. 
At $600^{\circ} \mathrm{C}$ steady-state values were observed at all measured gas concentrations. The response and recovery times were $20-40 \mathrm{~s}$ and $2 \mathrm{~min}$, respectively. Figure 2 shows the linear correlation between the EMF saturation values and the logarithm of gas concentration at different operating temperatures. By increasing the temperature, the EMF response decreased at all different gas concentrations. The largest sensitivity $(18.8 \mathrm{mV} /$ decade $)$ was found at $600^{\circ} \mathrm{C}$. At temperatures below $550^{\circ} \mathrm{C}$, the sensing responses were unstable. For $\mathrm{Au} / \mathrm{YSZ} / \mathrm{Au} / \mathrm{WO}_{3}$ sensors below $650^{\circ} \mathrm{C}$ the $\mathrm{NO}_{2}$ response was very slow though the response magnitude was large. Fast and stable responses were observed at $650^{\circ} \mathrm{C}$ with a sensitivity of $17.3 \mathrm{mV} /$ decade.

In the presence of various $\mathrm{CO}$ concentrations the EMF response of $\mathrm{Pt} / \mathrm{YSZ} / \mathrm{Pt} / \mathrm{WO}_{3}$ sensors increased in the negative direction, unlike $\mathrm{NO}_{2}$ response (always keeping $\mathrm{WO}_{3}$ side at the positive terminal). At $600^{\circ} \mathrm{C}$ the $\mathrm{EMF}$ values at any given concentration were much smaller than those measured in the presence of $\mathrm{NO}_{2}$. However, the sensitivity at $600^{\circ} \mathrm{C}$ was $-15 \mathrm{mV} /$ decade, comparable to $\mathrm{NO}_{2}$ sensitivity at the same temperature. An attempt to decrease the $\mathrm{CO}$ cross sensitivity was successful when $\mathrm{Pt}$ electrodes were replaced with $\mathrm{Au}$. At $650^{\circ} \mathrm{C}$ the $\mathrm{CO}$ sensitivity of $\mathrm{Au} / \mathrm{YSZ} / \mathrm{Au} / \mathrm{WO}_{3}$ sensors dropped from -7 to $-4.0 \mathrm{mV} /$ decade, while at the same temperature the $\mathrm{NO}_{2}$ sensitivity was $17.3 \mathrm{mV} /$ decade. Figure 3 shows the $\mathrm{CO}$ sensitivity curves of $\mathrm{Pt} / \mathrm{YSZ} / \mathrm{Pt} / \mathrm{WO}_{3}$ and $\mathrm{Au} / \mathrm{YSZ} / \mathrm{Au} /$ $\mathrm{WO}_{3}$ sensors at 600 and $650^{\circ} \mathrm{C}$.

Figure 4 shows the amperometric measurements of $\mathrm{Au} / \mathrm{YSZ} / \mathrm{Au} / \mathrm{WO}_{3}$ sensors upon exposure to air and $1000 \mathrm{ppm}$ of $\mathrm{NO}_{2}$ and $\mathrm{CO}$ in air. A typical non-linear current-voltage characteristic was observed at all different atmospheres. At a given voltage, the current decreased in the presence of $\mathrm{NO}_{2}$ and increased in the presence of $\mathrm{CO}$.

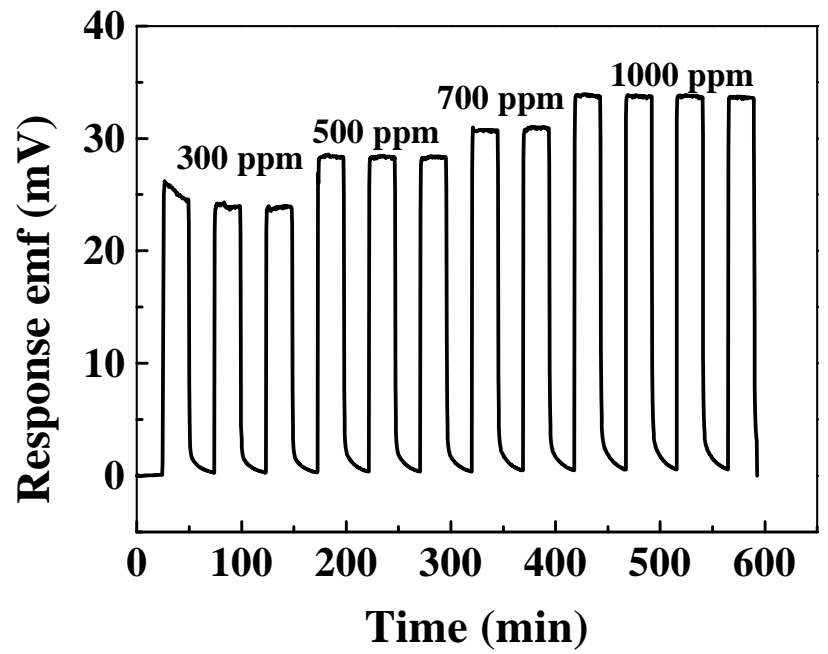

Figure 1. EMF response of $\mathrm{Pt} / \mathrm{YSZ} / \mathrm{Pt} / \mathrm{WO}_{3}$ sensor at $600^{\circ} \mathrm{C}$ in cycling air and $100 \mathrm{ppm}$ of $\mathrm{NO}_{2}$ in air.
The electrochemical reactions for $\mathrm{NO}_{2}$ and $\mathrm{CO}$ occurring at the three-phase boundary between solid electrolyte, electrode and gas, can be expressed as follows (Miura and Yamazoe 2000):

$$
\begin{aligned}
& \mathrm{NO}_{2}+2 e \Leftrightarrow \mathrm{O}^{2-}+\mathrm{NO}\left(\mathrm{WO}_{3} \text { side }\right) \\
& \mathrm{O}^{2-} \Leftrightarrow \frac{1}{2} \mathrm{O}_{2}+2 e(\text { metal electrode side }) \\
& \mathrm{CO}+\mathrm{O}^{2-} \Leftrightarrow \mathrm{CO}_{2}+2 e\left(\mathrm{WO}_{3} \text { side }\right) \\
& \frac{1}{2} \mathrm{O}_{2}+2 e \Leftrightarrow 2 \mathrm{O}^{2-}(\text { metal electrode side }) .
\end{aligned}
$$

The number of oxygen ions accumulated at the $\mathrm{WO}_{3}$ $(\mathrm{Pt}, \mathrm{Au}) / \mathrm{YSZ}$ and $\mathrm{YSZ} / \mathrm{Pt}(\mathrm{Au})$ interfaces is different and can be strongly influenced by the electrode material, its surface morphology and electrocatalytic activity. The porous layer of $\mathrm{WO}_{3}$ enhances the adsorption of gas molecules and hence highly promotes reactions (1) and

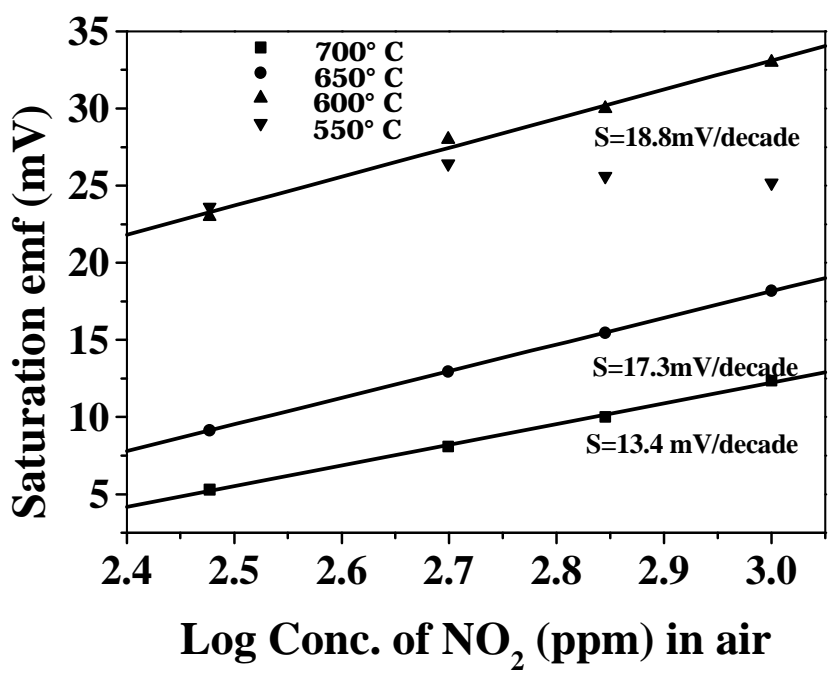

Figure 2. EMF of $\mathrm{Pt} / \mathrm{YSZ} / \mathrm{Pt} / \mathrm{WO}_{3}$ sensor vs $\log$ of $\mathrm{NO}_{2}$ concentration at different temperatures.

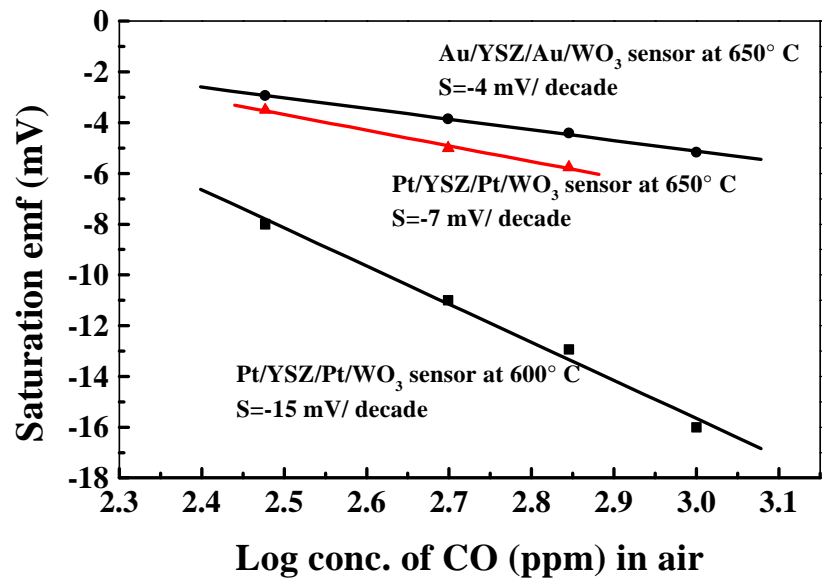

Figure 3. EMF of $\mathrm{Pt} / \mathrm{YSZ} / \mathrm{Pt} / \mathrm{WO}_{3}$ and $\mathrm{Au} / \mathrm{YSZ} / \mathrm{Au} / \mathrm{WO}_{3}$ sensors vs $\log$ of $\mathrm{NO}_{2}$ concentration at 600 and $650^{\circ} \mathrm{C}$. 


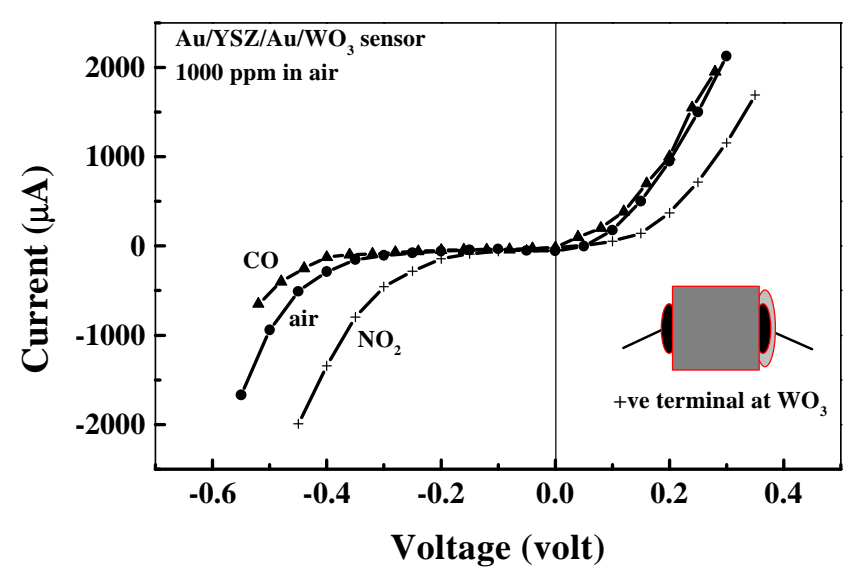

Figure 4. Amperometric measurements characteristics of $\mathrm{Au} /$ $\mathrm{YSZ} / \mathrm{Au} / \mathrm{WO}_{3}$ sensors upon exposure to air and $1000 \mathrm{ppm}$ of $\mathrm{NO}_{2}$ and $\mathrm{CO}$ in air at $650^{\circ} \mathrm{C}$.

(2) upon exposure of $\mathrm{NO}_{2}$ and $\mathrm{CO}$, respectively. Upon applied potential, the decrease in the current observed upon $\mathrm{NO}_{2}$ exposure can be related to the increase in the resistance and reactance at the electrolyte/oxide electrode interface due to an increase in the number of oxygen ions accumulated at the $\mathrm{WO}_{3}(\mathrm{Pt}, \mathrm{Au}) / \mathrm{YSZ}$ interface. Under positive bias voltage the current flow is very small. For $\mathrm{NO}_{2}$ exposure, under negative bias voltage, the oxygen ions move from higher to lower accumulation region (metal electrode side) and hence the current flow increases. The opposite behaviour is observed upon $\mathrm{CO}$ exposure. Since the $\mathrm{CO}$ sensitivity of sensors with $\mathrm{Au}$ electrodes is much lower than the $\mathrm{NO}_{2}$ sensitivity, a small difference in the current values was observed with respect to the amperometric measurements in air. The amperometric measurements clearly showed that the sensing reaction took place at the $\mathrm{WO}_{3}$ electrode.

\section{Conclusions}

YSZ-based electrochemical sensors with a $\mathrm{WO}_{3}$ auxiliary oxide electrode and $\mathrm{Pt}$ or $\mathrm{Au}$ electrodes were found to show stable and fast response in the temperature range $600-700^{\circ} \mathrm{C}$ in the presence of $\mathrm{NO}_{2}$. The high operating temperatures make these sensors suitable for automotive applications. The use of Au electrodes instead of Pt significantly lowers the response to $\mathrm{CO}$, improving the selectivity of the sensors. The role of $\mathrm{WO}_{3}$ as auxiliary electrode was established as crucial in the sensing mechanism of gases.

\section{Acknowledgements}

One of the authors (AD) gratefully acknowledges the "Programme for Training and Research in Italian Laboratories, ICTP, Trieste", Financial support by the National Research Council (CNR) under the frame of the Project MSTA II and the Ministry of University and Scientific and Technological Research of Italy (MURST).

\section{References}

Brosha E L, Mukundan R, Brown D R, Garzon F H, Visser J H, Zanini M, Zhou Z and Logothetis E M 2000 Sensors and Actuators B69 171

Grilli M L, Di Bartolomeo E and Traversa E 2001 J. Electrochem. Soc. 148 H98

Hibino T, Hashimoto A, Kakimoto S and Sano M $2001 \mathrm{~J}$. Electrochem. Soc. 148 H1

Ménil F, Coillard V and Lucat C 2000 Sensors and Actuators B67 1

Miura N and Yamazoe N 2000 in Sensors update (eds) H Baltes, W Göpel and J Hesse (Weinheim, Germany: WileyVCH) Vol. 6, pp. 191-210 